\title{
Urgences
}

\section{Questions d'URGENCES}

\section{Le comité de direction}

Numéro 1, 2e trimestre 1981

URI : https://id.erudit.org/iderudit/025000ar

DOI : https://doi.org/10.7202/025000ar

Aller au sommaire du numéro

Éditeur(s)

Urgences

ISSN

0226-9554 (imprimé)

1927-3924 (numérique)

Découvrir la revue

Citer ce document

Le comité de direction (1981). Questions d'URGENCES. Urgences, (1), 3-4.

https://doi.org/10.7202/025000ar d'utilisation que vous pouvez consulter en ligne.

https://apropos.erudit.org/fr/usagers/politique-dutilisation/ 
Une revue littéraire pour l'Est du Québec c'était une "urgence"!

Pour les auteurs de la région Bas St-Laurent - Gaspésie Iles-de-la-Madeleine, la revue répond même à plusieurs "urgences". Celle d'abord de disposer soi-même de sa propre culture, d'en être les dépositaires véritables et d'en faciliter la manifestation. Celle ensuite de faire connaître à nos concitoyens la quantité et la qualité des écrivains d'ici de même que la diversité de leurs intérêts et de leurs préoccupations. Celle encore pour une région comme la nôtre de voir la littérature qui se crée en son sein rayonner vers l'extérieur afin d'être mieux en mesure de saisir la portée de sa propre voix.

Et s'il fallait les nommer toutes, la liste serait impressionnante puisqu'il faudrait citer plus de cent trente "écriveux" recensés en 1979 sur le territoire de la région dite 01.

Qu'on y songe! Plus de cent trente personnes dont la parole, dont l'écrit, sont des outils quotidiens de travail sur eux-mêmes et sur leur environnement humain. On se croirait chez les "envahisseurs".

Bref, URGENCES sera le premier véritable instrument que se sera donné le Regroupement des auteurs de l'Est du Québec pour contribuer à la connaissance des auteurs de la région et pour faciliter la diffusion de leurs travaux. Un outil idéal, qui passera partout, qui s'offrira en cadeau à Noël, que l'on retrouvera dans toute bonne librairie ou dans sa case postale et que l'on lira assis, couché ou debout... 
Avec un tant soit peu de sérieux, nous qualifions nous-mêmes cet événement $d$ 'historique afin que les personnes concernées le sachent bien et réservent une place privilégiée au mois d'avril 81 dans leur mémoire.

Si le Regroupement des auteurs de l'Est du Québec promet à ses membres un véhicule de diffusion qui saura leur reconnaître une place importante, il s'engage également à offrir aux lecteurs une revue littéraire de première qualité qui leur proposera une parole très large dans son esprit et dans sa forme puisqu'elle appartient à un si grand nombre d'individus. En bref, URGENCES ne sera régionale qu'à cause de la grande majorité de ses artisans qui sont de la région et ne sera pas régionaliste à cause de l'universalité des thèmes explorés et de son ouverture relative aux auteurs de l'extérieur. La distribution d'URGENCES sera prioritairement régionale puis ensuite pan-québécoise dans un avenir rapproché.

On boira donc trois fois l'an dans URGENCES ce qui se distille ici en fait de poésie, de contes, de nouvelles, d'essais, de théâtre et de romans; nous publierons également des articles portant sur la littérature et la critique littéraire. On pourra certainement s'y "agrandir le cerveau par en-dedans" pour emprunter la formule d'un auteur de chez-nous dont c'est le souci constant.

Place maintenant à dix-sept auteurs de l'Est du Québec qui, nous l'espérons, vous convaincront de la réelle urgence d'URGENCES. Et pour nous ça presse! 